\title{
Human astrovirus infection associated with encephalitis in an immunocompetent child: a case report
}

\author{
Georgia Koukou', Sandra Niendorf ${ }^{2}$, Britt Hornei $^{3}$, Jan-U Schlump ${ }^{1}$, Andreas C. Jenke ${ }^{1,4^{*}}$ (D) and Sonja Jacobsen ${ }^{2}$
}

\begin{abstract}
Background: Until today, classic human astroviruses have not been associated with central nervous system infections in immunocompetent patients.

Case presentation: A 16-month-old Caucasian girl presented with repetitive generalized seizures with a 4-day history of watery diarrhea, which had already gradually improved. Initially, the prolonged seizures ceased after systemic midazolam treatment and were thought to be fever associated. However, her mental status remained altered, and after seizure recurrence, she was transferred to our pediatric intensive care unit. Seizure control was achieved by a combination of high-dose levetiracetam and phenobarbital, but she remained unconscious. An electroencephalogram at this time revealed generalized high voltage theta activity. All laboratory analyses, including extended blood and cerebrospinal fluid analyses, and a brain magnetic resonance imaging were normal.

On day 4, the child gradually became conscious, but was very agitated and not able to walk. Since an electroencephalogram at this time still revealed generalized high voltage theta activity, although she had not received sedative medications for 72 hours, she was diagnosed as having encephalopathy. At that time, results of diagnostic testing of the stool sample were positive for classic astrovirus infection, and we decided to analyze the initially obtained cerebrospinal fluid for astrovirus as well. Cerebrospinal fluid was also found positive for human astrovirus. Sequencing analysis revealed a classic astrovirus genotype 1 with exactly the same nucleotide sequence as in the feces. Clinically, the child gradually improved and was discharged on day 9.

Conclusions: Whereas the new human astrovirus subtypes have been recently associated with central nervous system infection, this is the first case of encephalitis in an immunocompetent child due to classic human astrovirus. Considering that classic human astroviruses are the third most common etiological agents of viral gastroenteritis in children, we believe that human astroviruses as causative agents for central nervous system infections should be considered more often, especially in children and infants with preceding gastroenteritis.
\end{abstract}

Keywords: Classic human astroviruses, CNS infections, Encephalitis, Immunocompetent, Gastroenteritis

\section{Background}

Human astroviruses (HAstVs) were first identified in 1975 in stool samples from children with diarrhea. Until recently, the gastrointestinal tract had been considered the main site of infection with particularly severe acute

\footnotetext{
* Correspondence: andreas.jenke@uni-wh.de; andreas.jenke@klinikumkassel.de

${ }^{1}$ EKO Children's Hospital, Witten/Herdecke University, Virchowstr. 20, Oberhausen, Germany

${ }^{4}$ Children's Hospital Kassel, Witten/Herdecke University, Alfred-Herrhausen Str. 40, Witten, Germany

Full list of author information is available at the end of the article
}

gastroenteritis in children. Recently, highly divergent strains of astroviruses named Melbourne (MLB) and Virginia/Human-Mink-Ovine-like (VA/HMO) were discovered, which are phylogenetically markedly distant from the classic HAstV. These novel HAstVs have been identified as the cause of central nervous infections such as meningitis and encephalitis, especially in immunocompromised children with gastrointestinal symptoms. To date, only one case has been described in which the classic HAstV genotype four has been associated with central nervous system (CNS) infections in a

(c) The Author(s). 2019 Open Access This article is distributed under the terms of the Creative Commons Attribution 4.0 International License (http://creativecommons.org/licenses/by/4.0/), which permits unrestricted use, distribution, and 
hospitalized infant with severe combined immunodeficiency (SCID) in Switzerland [1].

\section{Case presentation}

A 16-month-old Caucasian girl presented with prolonged, generalized, repetitive tonic-clonic seizures to our emergency department. She had watery diarrhea with a low-grade fever up to $38.4{ }^{\circ} \mathrm{C}$ and new types of seizures 4 days before. Two months earlier, she was admitted to our neuropediatric ward due to suspected generalized seizures. At that time, her psychomotor development and all clinical and laboratory findings, such as cerebrospinal fluid (CSF) status, electroencephalography as well as a cerebral magnetic resonance imaging (MRI) were normal. After a video documentation, a diagnosis of breath-holding spells was made. On admission day, she was unconscious with a generalized tonic-clonic seizure for approximately 20 minutes. At our emergency department, she received $5 \mathrm{mg}$ midazolam buccal and the seizures subsided. She was then transferred to the general pediatric ward under the impression of a febrile seizure. However, during the

Table 1 Blood parameters

\begin{tabular}{|c|c|c|c|}
\hline Complete blood count & Reference range & Day of admission & Day 3 \\
\hline Leukocytes & $6.2-15 \times 10^{3} / \mu l$ & $5.9 \times 10^{3} / \mu \mathrm{l}$ & $4.6 \times 10^{3} / \mu \mathrm{l}$ \\
\hline Erythrocytes & $4.1-5.0 \times 10^{12} / \mu \mathrm{l}$ & $4.3 \times 10^{12} / \mu \mathrm{l}$ & $4.17 \times 10^{12} / \mu l$ \\
\hline Hemoglobin & $10.3-12.4 \mathrm{~g} / \mathrm{l}$ & $12.0 \mathrm{~g} / \mathrm{l}$ & $11.8 \mathrm{~g} / \mathrm{l}$ \\
\hline Hematocrit & $26-37 \%$ & $36 \%$ & $33 \%$ \\
\hline MCV & $81-99 \mathrm{fl}$ & $82 \mathrm{fl}$ & $80 \mathrm{fl}$ \\
\hline $\mathrm{MCH}$ & 23-28 pg/cell & 28 pg/cell & 28 pg/cell \\
\hline $\mathrm{MCHC}$ & $32-36 \mathrm{~g} / \mathrm{dl}$ & $33.8 \mathrm{~g} / \mathrm{dl}$ & $35.5 \mathrm{~g} / \mathrm{dl}$ \\
\hline Thrombocytes & $130-450 \times 10^{3} / \mu l$ & $267 \times 10^{3} / \mu \mathrm{l}$ & $255 \times 10^{3} / \mu \mathrm{l}$ \\
\hline Normoblasts \% & & $0.1 \%$ & \\
\hline Neutrophils \% & $21-67 \%$ & $50 \%$ & \\
\hline Lymphocytes \% & $20-64 \%$ & $35 \%$ & \\
\hline Monocytes \% & $5-11 \%$ & $14 \%$ & \\
\hline Eosinophils \% & $0-4 \%$ & $1 \%$ & \\
\hline Basophils \% & $0-1 \%$ & $0 \%$ & \\
\hline Chemistry panel & Reference range & Day of admission & Day 3 \\
\hline Urea & $17-43 \mathrm{mg} / \mathrm{dl}$ & 33 mg/dl & $11 \mathrm{mg} / \mathrm{dl}$ \\
\hline Creatinine & $0.6-1.1 \mathrm{mg} / \mathrm{dl}$ & $0.44 \mathrm{mg} / \mathrm{dl}$ & $0.37 \mathrm{U} / \mathrm{I}$ \\
\hline CK & $<247 \mathrm{U} / \mathrm{I}$ & & $75 \mathrm{U} / \mathrm{l}$ \\
\hline GOT & $<82 \mathrm{U} / \mathrm{l}$ & $75 \mathrm{U} / \mathrm{l}$ & $49 \mathrm{U} / \mathrm{l}$ \\
\hline GPT & $<30 \mathrm{U} / \mathrm{l}$ & $17 \mathrm{U} / \mathrm{l}$ & $15 \mathrm{U} / \mathrm{l}$ \\
\hline LDH & $<300 \mathrm{U} / \mathrm{I}$ & & $241 \mathrm{U} / \mathrm{I}$ \\
\hline CRP & $<0.5 \mathrm{mg} / \mathrm{dl}$ & $<0.2 \mathrm{mg} / \mathrm{dl}$ & $<0.2 \mathrm{mg} / \mathrm{dl}$ \\
\hline Ammonia & $16-53 \mu \mathrm{mol} / / \mathrm{l}$ & $34.9 \mu \mathrm{mol} / \mathrm{l}$ & $41.6 \mu \mathrm{mol} / \mathrm{l}$ \\
\hline Magnesium & $0.77-1.03 \mathrm{mmol} / \mathrm{l}$ & & $0.77 \mathrm{mmol} / \mathrm{l}$ \\
\hline Potassium & $3.4-4.5 \mathrm{mmol} / \mathrm{l}$ & $4.0 \mathrm{mmol} / \mathrm{l}$ & $4.3 \mathrm{mmol} / \mathrm{l}$ \\
\hline Sodium & $136-146 \mathrm{mmol} / \mathrm{l}$ & $143 \mathrm{mmol} / / \mathrm{l}$ & $141 \mathrm{mmol} / /$ \\
\hline Calcium & $1.15-1.29 \mathrm{mmol} / \mathrm{l}$ & $1.27 \mathrm{mmol} / \mathrm{l}$ & $1.22 \mathrm{mmol} / \mathrm{l}$ \\
\hline Glucose & $70-105$ mg/dl & 74 mmol/l & 87 mmol/l \\
\hline Chloride & 98-106 mmol/l & $108 \mathrm{mmol} / / \mathrm{l}$ & $104 \mathrm{mmol} / \mathrm{l}$ \\
\hline $\mathrm{HbA} 1 \mathrm{c} \%$ & $<6 \%$ & $4.8 \%$ & \\
\hline Cortisol & $6.7-22.6 \mu \mathrm{g} / \mathrm{dl}$ & $22.3 \mu \mathrm{g} / \mathrm{dl}$ & \\
\hline АCTH & $4.7-48.8 \mathrm{pg} / \mathrm{ml}$ & $15.8 \mathrm{pg} / \mathrm{ml}$ & \\
\hline
\end{tabular}

ACTH adrenocorticotropic hormone, $C K$ creatine kinase, CRP C-reactive protein, GOT glutamic oxaloacetic transaminase, GPT glutamate-pyruvate transaminase, $H b A 1 c$ glycated hemoglobin, $L D H$ lactate dehydrogenase, $M C H$ mean corpuscular hemoglobin, $M C H C$ mean corpuscular hemoglobin concentration, $M C V$ mean corpuscular volume 
Table 2 Cerebrospinal fluid parameters

\begin{tabular}{ll}
\hline Cerebrospinal fluid results \\
\hline Cell count & $1 / 3 / \mu \mathrm{l}$ \\
Glucose & $60 \mathrm{mg} / \mathrm{dl}$ \\
Protein & $12.6 \mathrm{mg} / \mathrm{dl}$ \\
Lactate & $12.4 \mathrm{mg} / \mathrm{dl}$ \\
Epstein-Barr & Negative \\
virus DNA & \\
Astrovirus PCR & Positive \\
Herpes virus 1 & Negative \\
and 2 & \\
Enteroviruses & Negative \\
Isoelectric & No sign of oligoclonal bands (serum and CSF) \\
focusing & \\
Reibergram & Acute inflammatory process with intrathecally \\
& produced lgG and IgM, normal CSF barrier function
\end{tabular}

CSF cerebrospinal fluid, IgG immunoglobulin G, IgM immunoglobulin $\mathrm{M}, P C R$ polymerase chain reaction

following hours seizures reoccurred. She received levetiracetam intravenously up to a total dose of $50 \mathrm{mg} / \mathrm{kg}$ per day without a lasting effect. Full blood count, electrolytes, ammonia, blood gas analysis, inflammatory markers, and transaminases as well as ophthalmologic assessment were all repeatedly normal (Table 1 ). On day 2, she still had short generalized seizures and her consciousness deteriorated steadily so that a lumbar puncture was performed. Seizure control was only achieved after the application of phenobarbital $(30 \mathrm{mg} /$ $\mathrm{kg}$ ) and she was then transferred to the pediatric intensive care unit. At that point, electroencephalography showed an encephalopathic picture with a generalized high amplitude theta and delta activity. Seizure activity was not noted. A CSF examination showed no abnormalities. Her glucose level was $60 \mathrm{mg} / \mathrm{dl}$ (reference range $40-70 \mathrm{mg} / \mathrm{dl}$ ), protein level $12.6 \mathrm{mg} / \mathrm{dl}$ (reference range $15-45 \mathrm{mg} / \mathrm{dl}$ ), lactate level $12.4 \mathrm{mg} / \mathrm{dl}$ (reference range $<20 \mathrm{mg} / \mathrm{dl}$ ), and no cells were present. CSF was

Table 3 Stool parameters

\begin{tabular}{ll}
\hline Stool results & \\
\hline Campylobacter antigen (ELISA) & Negative \\
Astrovirus antigen (ELISA) & Positive \\
Adenovirus Antigen (ELISA) & Negative \\
Norovirus (PCR) & Negative \\
Rotavirus (PCR) & Negative \\
Salmonella (stool culture) & Negative \\
Shigella (stool culture) & Negative \\
Yersinia species (stool culture) & Negative \\
Clostridium difficile PCR (toxin A $+B$ ) & Negative \\
\hline ELISA enzyme-linked immunosorbent assay, PCR polymerase chain reaction
\end{tabular}

also negative for herpes simplex virus type 1 (HSV-1), herpes simplex virus type 2 (HSV-2), enteroviruses, and Epstein-Barr virus. Isoelectric focusing showed no oligoclonal bands, but a Reibergram revealed an intrathecal production of immunoglobulin (IgM) and immunoglobulin (IgG) indicating an acute inflammatory process (Table 2). On day 3 , she was still somnolent, so that a cerebral MRI was performed which showed no abnormalities. Electrolytes and glucose levels were repeatedly within normal limits (Table 1 ). On day 4 , she gradually became awake, but was very agitated and not able to walk. Electroencephalography revealed a generalized high voltage theta activity, even though she had not received any sedative medication for 72 hours. The results of the stool samples, which were obtained on the third day of her hospitalization, were negative for Campylobacter, Salmonella, Shigella, Yersinia species, norovirus, enterovirus, Rotavirus, and adenovirus except for HAstV (Table 3).

We then hypothesized an astrovirus-related CNS infection and tested the initially obtained CSF sample for the virus. Sanger sequencing revealed a classic genotype HAstV-1 with the same nucleotide sequence in both samples (Fig. 1). Initially, we considered a therapy with intravenous immunoglobulin (IVIG) \pm methylprednisolone, but abstained from it due to her fast and good clinical improvement [2]. Over the following days, she improved gradually, the electroencephalography normalized and on day 9 she was discharged. On follow-up over the next 6 months she showed a normal sensorimotor development without any signs of neurological impairment. Despite extensive investigations, we could not identify the source of the infection in this case. Most commonly described reservoirs and sources of infection for humans include fruits, vegetables, and water [2].

\section{Discussion and conclusions}

HAstVs constitute the third most common viral agent of acute diarrhea after Rotavirus and norovirus and are responsible for up to $10 \%$ of non-bacterial gastroenteritis [3]. However, the recently discovered highly divergent HAstVs, named MLB and VA/HMO, have been identified as the cause of CNS infections in vulnerable individuals highlighting that these viruses bypass the gastrointestinal tract and infect other tissues and organs [4]. HAstV-VA1/HMO-C has also been detected in the brain tissue of immunocompromised patients with acute encephalitis. Overall, CNS infection with the newly described HAstVs almost exclusively occurs in immunocompromised patients [5].

Here, we report the first case of a CNS infection with a classic $\mathrm{HAstV}$ in a non-immunocompromised infant. However, common CSF findings of CNS infections such as pleocytosis were in our case completely normal, 


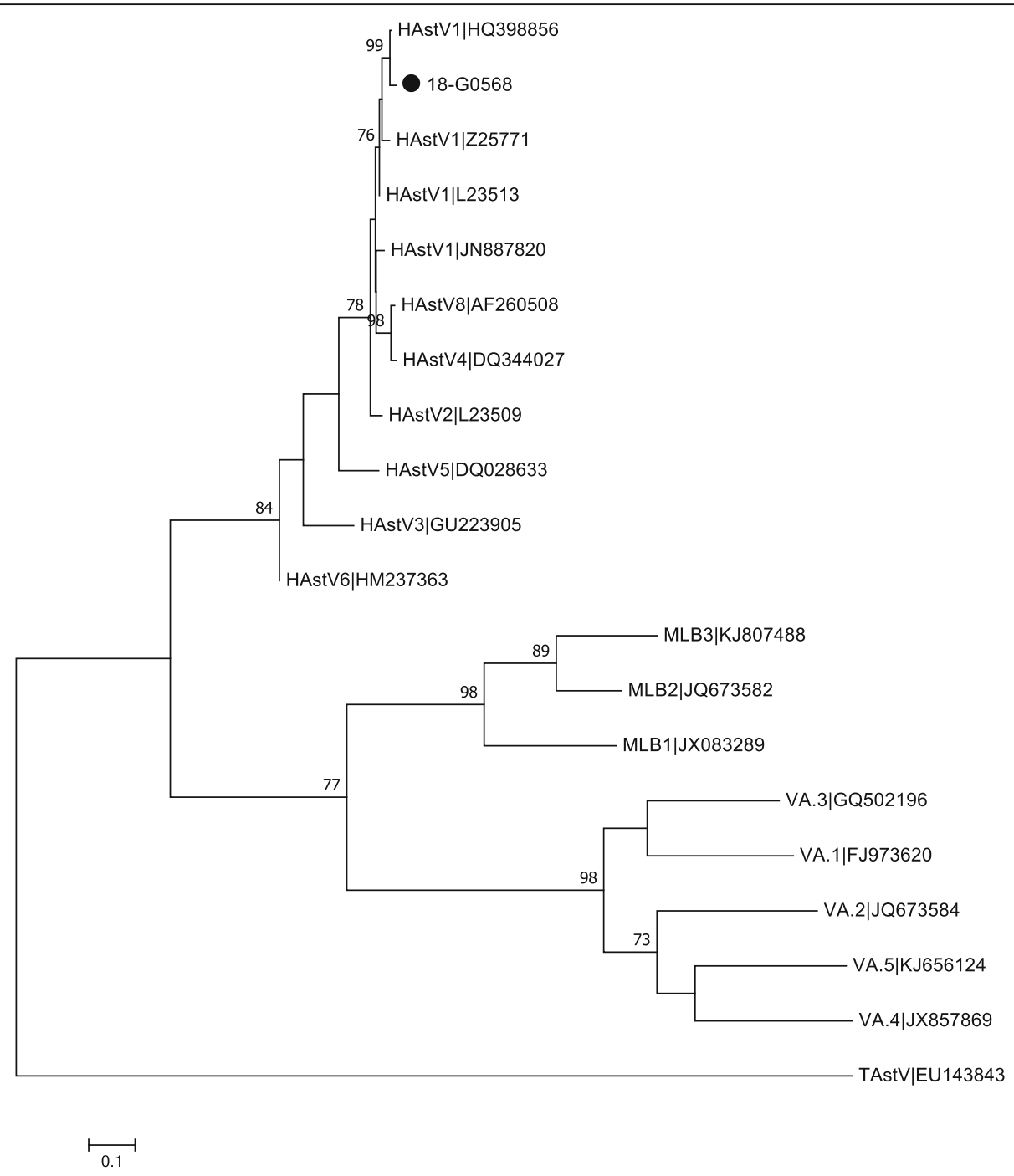

Fig. 1 The phylogenetic tree of a $410 \mathrm{bp}$ alignment of the ORF1b region of human astrovirus identified from the patient (18-G0568) belongs to the classic human astrovirus genotype human astrovirus-1. The tree was constructed using the Maximum Likelihood method and the Tamura-3parameter method with the Bootstrap test (1000 replicates). For the modeling of the evolutionary rate, a discrete gamma distribution model was used with MEGA 7. Bootstrap values above 70 are shown. Reference sequences obtained from the GenBank are indicated by the accession number, TAstV was used as an outgroup (GenBank EU143843). HAstV human astrovirus, MLB Melbourne, TAstV turkey astrovirus, VA Virginia

which is in line with previous reports [1]. Diagnosis of an astrovirus CNS infection is further complicated by the unreliable detectability of acute IgM antibodies in CSF and the fact that even serum antibodies in the acute phase of infection were detectable only in a few patients [6]. Therefore, the diagnosis of an acute astrovirus CNS infection currently relies exclusively on the clinical picture, specific detection of astrovirus in the CSF mostly by next-generation sequencing (NGS)-based diagnosis, and exclusion of other known causes for encephalitis, as in this case.

Similar to previous reports on immunocompromised patients and infection of HAstV-MLB or VA strains, the most probable route of infection was enteric inoculation followed by viral translocation and infection of the CNS via the bloodstream. In previous case reports, HAstVVA1 was found in neurons and astrocytes [7]. A recent publication showed for the first time that the novel described HAstV-VA1 could be propagated in cell culture without trypsin, which was mandatory for the cell culture of classic HAstV strains. The authors supposed that classic and novel HAstV genotypes react differently toward trypsin for the proteolytic cleavage of the viral capsid. This may influence the contribution of the tissue tropism of HAstVs and novel HAstV strains might spread toward tissues with low trypsin levels; however, so far the mechanism of neuroinvasion of HAstV remains unclear [8]. Interestingly, CNS infections in 
mammals such as swine, sheep, and cattle seem to be quite common [9].

We therefore believe that in the future the possibility of HAstV CNS infection needs to be considered on a routine basis in non-immunocompromised infants and young children with sensitive detection systems covering all HAstV species (classic HAstV genotypes 1 to 8 as well as HAstV-MLB and VA strains). Even though there are currently no specific therapeutic options available, the identification of the causative agent in an encephalopathic child is of utmost importance - for the community to implement prophylactic actions and even more for the parents who always seek to obtain an explanation - in particular, in possibly very debilitating diseases such as encephalopathy/encephalitis.

\section{Abbreviations}

CNS: Central nervous system; CSF: Cerebrospinal fluid; HAstV: Human astrovirus; HSV-1: Herpes simplex virus type 1; HSV-2: Herpes simplex virus type 2; IgG: Immunoglobulin G; IgM: Immunoglobulin M; IVIG: Intravenous immunoglobulin; MLB: Melbourne; MRI: Magnetic resonance imaging; NGS: Next-generation sequencing; SCID: Severe combined immunodeficiency; VA/HMO: Virginia/Human-Mink-Ovine-like

\section{Acknowledgements}

Not applicable.

\section{Authors' contributions}

GK and JU were responsible for the patient during the hospital course. JU and $\mathrm{AJ}$ interpreted the findings and were responsible for clinical decision making. GK and AJ wrote the manuscript. JU, SN, SJ, and BH critically reviewed the manuscript. SN and SJ performed genotyping and sequencing analysis of the virus. All authors read and approved the final manuscript.

Funding

There was no funding.

\section{Availability of data and materials}

All data generated or analyzed during this study are included in this published article. The datasets used and/or analyzed during the current study are available from the corresponding author on reasonable request.

\section{Ethics approval and consent to participate}

The author(s) declare no conflict of interest. There was no funding in this study. The study was approved by the Ethics committee of Witten/Herdecke University and performed in accordance with the Declaration of Helsinki.

\section{Consent for publication}

Written informed consent from the legal parents on behalf of their child for the publication of this manuscript and any accompanying medical data was obtained. A copy of the written consent is available for review by the Editorin-Chief of this journal.

\section{Competing interests}

The authors declare that they have no competing interests.

\section{Author details}

'EKO Children's Hospital, Witten/Herdecke University, Virchowstr. 20, Oberhausen, Germany. ${ }^{2}$ Consultant Laboratory for Noroviruses, Unit Viral Gastroenteritis and Hepatitis Pathogens and Enteroviruses, Department of Infectious Diseases, Robert Koch Institute, Seestraße 10, 13353 Berlin, Germany. ${ }^{3}$ EKO Department of Laboratory Medicine and Microbiology, Virchowstr. 20, Oberhausen, Germany. ${ }^{4}$ Children's Hospital Kassel, Witten/ Herdecke University, Alfred-Herrhausen Str. 40, Witten, Germany.
Received: 4 April 2019 Accepted: 24 October 2019

Published online: 23 November 2019

References

1. Lum SH, et al. An emerging opportunistic infection: fatal astrovirus (VA1/ HMO-C) encephalitis in a pediatric stem cell transplant recipient. Transplant Infect Dis. 2016;18:960-4. https://doi.org/10.1111/tid.12607.

2. Reuter G, Pankovics P, Boros A. Nonsuppurative (Aseptic) Meningoencephalomyelitis Associated with Neurovirulent Astrovirus Infections in Humans and Animals. Clin Microbiol Rev. 2018;31 https://doi. org/10.1128/CMR.00040-18.

3. Bosch A, Pinto RM, Guix S. Human astroviruses. Clin Microbiol Rev. 2014;27: 1048-74. https://doi.org/10.1128/CMR.00013-14.

4. Cordey S, et al. Astrovirus MLB2, a New Gastroenteric Virus Associated with Meningitis and Disseminated Infection. Emerg Infect Dis. 2016;22:846-53. https://doi.org/10.3201/eid2205.151807.

5. Brown JR, et al. Astrovirus VA1/HMO-C: an increasingly recognized neurotropic pathogen in immunocompromised patients. Clin Infect Dis. 2015;60:881-8. https://doi.org/10.1093/cid/ciu940.

6. Belliot G, Laveran H, Monroe SS. Outbreak of gastroenteritis in military recruits associated with serotype three astrovirus infection. J Med Virol. 1997:51:101-6.

7. Naccache $\mathrm{SN}$, et al. Diagnosis of neuroinvasive astrovirus infection in an immunocompromised adult with encephalitis by unbiased next-generation sequencing. Clin Infect Dis. 2015;60:919-23. https://doi.org/10.1093/cid/ ciu912.

8. Janowski AB, Bauer IK, Holtz LR, Wang D. Propagation of astrovirus VA1, a neurotropic human astrovirus, in cell culture. J Virol. 2017; https://doi.org/10. 1128/JVI.00740-17.

9. Arruda B, et al. Porcine Astrovirus Type 3 in the Central Nervous System of Swine with Polioencephalomyelitis. Emerg Infect Dis. 2017;23:2097-100. https://doi.org/10.3201/eid2312.170703.

\section{Publisher's Note}

Springer Nature remains neutral with regard to jurisdictional claims in published maps and institutional affiliations.
Ready to submit your research? Choose BMC and benefit from:
- fast, convenient online submission
- thorough peer review by experienced researchers in your field
- rapid publication on acceptance
- support for research data, including large and complex data types
- gold Open Access which fosters wider collaboration and increased citations
- maximum visibility for your research: over $100 \mathrm{M}$ website views per year
At BMC, research is always in progress.
Learn more biomedcentral.com/submission 